\title{
Progress in Forest Insect Control in Canada.
}

\author{
By
}

J.M. Swaine.

The spruce budworm (Cacoecia fumiferana Clem.) outbreak that swept through our eastern forests some years ago was probably the most destructive infestation of the sort that has ever been recorded. Myriads of budworm caterpillars fed on the foliage of balsam fir and spruce in the province of Quebec south of the height of land, and in the Maritime Provinces, and as a result of their depredations, a very large part of the fir and of the red spruce of the East was killed. It has been estimated that between 100 and 200 million cords of pulpwood were destroyed. It is impossible to estimate the amount at all exactly since no one knew the amount of the original stand; but 150 million cords is probably a conservative estimate of the losses up to this time. This outbreak is still extending in Central Ontario, west of Lake Temagami, and has not yet ceased its activity in $\mathrm{C}_{a}$ pe Breton and Antogonish County in Nova Scotia. Recent smaller outbreaks have occurred also in Western Ontario and in Northern Manitoba.

Officers of the Division of Forest Insects of the Entomological Branch, Department of Agriculture for Canada, have studied this outbreak intensively throughout a great part of the infested territory and their investigations are still proceeding in connection with peculiar features of the present outbreaks in Nova Scotia and Central Ontario. A large amount of valuable information has now been obtained and will be available for future workers. As a result of this study it was found that the greatest injury has been in and near the mature stands containing a large percentage of balsam and red spruce. White spruce and black spruce were rarely killed at all extensively in Quebec and New Brunswick, although white spruce is apparently being seriously affected in the present Ontario outbreak.

The opinion has been published repeatedly by officers of this Division that the danger of extensive budworm outbreaks in the future would be connected with mature stands containing a large percentage of balsem fir and we have accordingly recommended urgently that pulpwood companies regulate their cutting so as to remove the over-mature balsam stands as rapidly as possible, and thereafter systematically cut the older stands first. If this recommendation is followed systematically, and it is perfectly feasible on many limits at least, there will eventually be produced throughout a large part of our eastern pulpwood forests a fast-growing, vigorous 
stand of balsam and spruce, cut on a short rotation, in which,it seems probable, an extensive budworm outbreak would never develop.

In the meantime, it is necessary, if possible, to discover some means of direct control, that may be applied to the more valuable areas at least, when budwom outbreaks appear.

Since the budworm is a native insect, there is only a limited opportunity for obtaining relief through the importation and distribution of parasites. It seems possible that the perasites of some allied European specis might attack the budworm if they could be established in our forests. This subject is being studied and arrangements have been made to test the usefulness of imported parasites at the earliest opportunity.

The distribution of poison dusts over the infested forest by means of air machines has seemed to offer more hope of direct control than any other method. This method has been employed with success for the control of other deioliating forest caterpillars. both in the United States and Europe, but there are two factors which render it difficult of application to budworm outbreaks. The budworm feeds, in many cases, by boring into the buds before the latter have fully opened, and the buds of a mixed coniferous stand open irregularly. It is desirable to apply the dust while the caterpillars are small, since they are then most easily killed, but at that time they are most likely to be boring in the partly opened buds and therefore in great measure protected from the dust. When the buds of balsam fir: are open sufficiently to permit the dust to penetrate to the axis, those of red spruce, which open from one to three weeks later, are usually closed or only partly open, so that it will often be difficult to dust a mixed stand effectively. There is the further difficulty that the dust must be applied within a short period of time and in the early season when veather conditions are likely to be unfavourable, and, in addition, the cost of the operetion might be prohibitive.

Nevertheless, the possibility of success appeared to be sufficiently great to warrant a series of thorough experiments. If a method of dusting could be perfected by which the budworm could be destroyed effectively, even though at considerable cost, it might prove to be of incalculable value in protecting valuable stands of timber or even in checking the development of incipient outbreaks.

It was accordingly arranged, through co-operation between the Entomological Branch of the Canadian Department of Agriculture and the Canadian Air Service, and consultation with the Dominion Forest Service, to conduct an airplane dusting experiment last spring on the spruce budworm outbreak in Cape Breton Island. The Canadian Air Service provided a special dusting airplane, with a pilot, mechanics

$$
36
$$


and the necessary equipment. The Department of Agriculture provided the dust and planned and supervised the experiment with the co-operation of the Nova Scotia Forest Branch, which also provided a large amount of dust for a continuation of the experiment which they supervised on a budworm outbreak in Antigonish County on the mainland of Nova Scotia. The whole method of procedure was new under the forest conditions which obtained in that outbreak; the best plots available were composed of mixed stands of balsam, spruce and hardwoods on which the infestation was only moderately heavy; the balsam buds opened very irregularly and consequently the balsam buds were ready for dusting at a time when the spruce buds were still largely unopened; unfavourable weather conditions developed at the period when the dusting ropuired to bo done: great difficulty was experienced in marking the plots so that their boundaries could be clearly discerned by the pilot when flying low over the tree tops; and, in addition, some trouble was experionced with uneven liberation of dust from the hopper.

These difficulties were eventually surmounted, however, and the dust vas applied in different doses to most of theselected plots with a fair degree of exactness. The work had to be discontinued before all the largest plots were treated owing to the lateness of tho sors on.

The work was successful in that the officers engaged upon it learned how to conduct such an experiment, in itself a long step in advance, and valuable information was obtained respocting the effect of different amounts of poison on different stages of the caterpillars. The effect of the different doses, however, was not sufficiently clear cut to enable definite recominendetions to be made. With the experience obtained in last season's experiment it should be possible to proceed with the investigetion, and establish definitely the valuo of airplane dusting for the control of budworm outbreaks as well as for other outbroaks of defoliating forost insects, with the hope of perfecting this method for practical use in our forests.

In the yollow pine forests of British Columbia during the past six years, a vigorous campaign has been conducted for the control of two destructive pests, the mountain pine beetlo, (Dendroctonus monticolao Hopk.) and tho westorn pine beetle, (Dendroctonus brevicomis Lec.) which throatenod to destroy the greater part of the whole yellow pine stand in the province. This work has been carried out under the supervision of tho Division of Forest Insects of the Intomological Branch of the Canadian Department of Agriculture in the closest possible co-operation with the Provincial Forest Branch and the Dominion Forest Service on the lands administered by them respectively. More than 50,000 beetlo-infested trees have been cut and burned in this control work at an approximate direct cost of $\$ 100,000$. It can now be stated that, with the com- 
pletion of last summer's control work, these destructive outbreaks have apparently been brought under: complete control, so that in the future we may reasonably expect that, provided logging slash is burned, careful annual inspections and an occasional small control operation should sufice to prevent the development of further outbreaks. Judging by all previous experience with these outbreaks in British Columbia and in similar regions in the western United States, this control work has saved the commercial yellow pine of British Columbia from almost wholesale destruction.

Outbreaks by the mountain pine beetle in lodgepole pine have also been dealt with, but with less satisfactory results. In lodgepole pine stands the infestation spreads with such rapidity that unless the control work is undertaken while the outbreak is very small there may be little hope for success.

It is reasonable to believe that these destructive outbreaks could be prevented in the future through an efficient system of annual inspections throughout the infested lodgepole pines tands and the prompt application of control work to each small outbreak as it is discovered. With this end in view it was arranged between the two Branches that special officers of the Division of Forest Insects stationed in British Columbia should visit the ranger stations of the Dominion Forest Service in lodgepole areas of British Columbia and Alberta and instruct the rangers in detecting and reporting lodgepole pine beetle outbreaks and in applying control measures. It is planned to continue this work in 1928 and a similar arrangement has been made with the Provincial Forest Branch. With the admirable system of co-operation that obtains among these theee Government organizations, we may confidently look forward to the tine when these destructive outbreaks will be prevented throughout the great lodgepole pine areas of Bitish Columbia and Alberta.

More than a generation ago a destructive outbreak of the larch or tamarack sawfly, (Lygaeonematus erichsoni Hartig.) swept throughout our esstern forests from the Atlantic Ocean to the Great Lakes and killed the greater part of the tamarack in all that area. It has since spread westward north of the prairies into northern British Columbia and threatens almost complete destruction of the tamarack stand.

In the eastern forests a new crop of larch is rapidly near ing commercial size and on this the sawfly is again developing to numbers that threaten its eventual destruction.

Owing to the characteristics of the sawfly outbreak and the low value and scattered nature of the stand of larch, direct control measures are hardly to be considered. Its native parasites are 
apparently rarely effective in preventing the almost complete destruction of the trees.

Since, however, this insect was probably imported originally from Burope, where it occurs at times in small outbreaks, but is not the destructive pest it has proven to be on this continent, it seemed possible that the introduction of its European parasites, not present in our country, might have very beneficial results. Importations of parasitized larch sawfly cocoons were accordingly made from fingland to this country by the Fntomological Brancit in the years 1912 and 1913.

Sinall colonies were placed at several stations in eastern Canada and much larger ones at the Spruce Wood Reserve and the Riding Mountains Reserve in Manitoba, on what was then the western margin of the outbreak.

Very recently it was discovered that the larch in the Spruce Woods Reserve were recovering their normal health and that the sawfly larvae were no longer abundant. At the same time the firopean parasite was found in considerable numbers parasitizing the few sawfly la rvae that remained. The imported parasitic species was also recovered last summer in the Riding Mountains Reserve. The information we have at present leads us to hope that a valuable European parasite of the larch sawfly has been successfully established in those two localities at least.

Last season the first shipment of parasitized cocoons was sent from the Spruce Woods Reserve to our parasite laboratory at Chatham, Ontario, and the parasites which were brod therefrom were subsequently liberated in an infested lorch stand at St. Williams, Ont. It is proposed to continue this work and to establish colonies of the paresites at selected stations in different parts of the sirefly infested area, both in the East and in the West. From these stations further distribution can be made, in the hope of establishing this parasite eventually throughout the whole area infested by the larch sawfly in this country.

It is well recognized that problems of the kind just described can be dealt with most of fectively through co-operation between the entpmologists and the foresters of the Canadian and provincial services and the forestry departments of private companies. The very gratifying degreo of co-operation that obtains at present can, we believe, be extended with great advante.ge.

It has already bean stated that the control of the lodgepole pine beetle outbreaks can be effected only through an inspection of the limits and the prompt application of control measuros in the initial stages of the infestations. If a mothod can be devised for controlling spruce budworm outbreaks effectively and cheaply through 
airplane dusting, or by any other method, it will be necessary to have a reliable means for obtaining information respecting outbreaks in their earliest stages. The samo principle applies generalIy in the control of forest insect outbreaks whenever control is, or in future becomes, possible.

It is evident that we neod an intelligence service by means of which reports on insects could be obtained systomatically from as many parts as possible of our conmercial jorost aroa. This need could bo mot, we cejieve, through an arrangoment botwoen the Canadian and provincial forest branchos, the Canodian National Parks Branch, the lumber and pulp associatjons and the forest entomologists whereby the latter could receive perindically roports on insect injuries throughout the sueson from rangors and association and company officials treveliing in tho forest.

It would necessarily requiro considerable time to perfect a system of this kjind, sireo thoso making tho reports would neod to be instructed in the injuries to be observed, throvgh the distribution of literature and, whenever possibie personal direction, but even in its initial stages much valuable information should bo obtainod. In measure, as the mon making the reports become familiar with the injuries, the information received should prove of increasing value in facilitating the salvage of infested timber. aa well as in the application of methods of control.

The Division of Forest Insects is proposing, after thorough consultation with the Dominion foresters, to submit shortly a plan for an intelligence service of the rature just described, and hopes for the support of the mombers of this socioty in making the schemo a. success. 